\title{
Adivinhas em Química
}

\author{
JOÃO CARLOS M. PAIVA *
}

Apresenta-se um conjunto de 25 adivinhas dirigidas a alunos do $8 .^{\circ}$ ano de escolaridade.

Aquelas que estão assinaladas com um asterisco, foram elaboradas por alunos.

Estas adivinhas têm-se revelado interessantes no que toca a aspectos de motivação e criatividade em relação aos alunos e foram até utilizadas em testes escritos com apreciável sucesso em termos de descontracção do aluno no decurso de provas escritas.

Um programa de computador bastante simples foi igualmente elaborado com este material. 0 computador pode orientar os alunos com algumas pistas, depois de uma primeira tentativa incorrecta, bem como acompanhar as adivinhas com um sistema de pontuação, que são, assim, apresentadas sob a forma do "Jogo das adivinhas".

Está a ser elaborado paralelamente um trabalho semelhante ao nivel do $9 .^{\circ}$ ano de escolaridade.

Já agora, tente adivinhar e, por favor, não espreite antecipadamente as soluções, apresentadas no final...

1 - Tenho protões e neutrões No global sou carregado. Rodeiam-me electrões 0 que me dá certo gozo. P'ra energia sou usado Mas ai sou bem perigoso...

2 - Tenho um nome popular 0 nome químico é diferente. Existo imenso no mar De oriente a ocidente. Sou um óptimo solvente E limpa sou transparente. Num laboratório normal Tenho de ser abundante. Minha fórmula é banal: Apenas uma vogal, Um dois e uma consoante.

3 - Dos átomos existentes, Sou eu o mais levezinho. Gases meus são comburentes Ardem logo num instantinho. Apesar de inteligentes... Damos erros bem terríveis... Não são gases comburentes Tais gases são combustíveis!
4 - Na água,

Grande soluço dou.

Na mesa dou paladar

E sou bom a conservar.

Abundante sou no mar,

Nas lágrimas também estou.

Igualmente surjo em minas,

E também saio das salinas.

Trata-me toda a gente

Com três letras somente

Mas o meu nome real

É um pouco diferente...

5 - Eu sou muito pequenino

E a matéria sou eu.

Baptizaram-me em menino,

Leucipo um nome me deu.

Eu nasci indivisivel

Até Thomson assim fui

De facto sou divisivel

Algo me constitui...

6 - Sou um átomo deficiente

Por falta ou excesso de electrões

Sei conduzir a corrente

Quando estou em soluções...

7 - Tendo um condensador, Um balão e as misturas,

Faço a separação

Com eficácia e vigor,

Obtendo substâncias puras

Duma dada solução.

Treino-me em refinarias

E se pensasses no petróleo,

Que dá gasolina e gasóleo

Concerteza acertarias...

8 - Sem papel não irás lá Tenho muita, muita pena.

Se a tua amostra é pequena,

Melhor ainda será.

Qual poderá ser então

Tal método de separação?

9* - Separei uma mistura

Com uma coisa engraçada.

Digamos que é muito dura

E atrai metal, mais nada!

Diz-me então se topaste

Que método será este.

Se disseres bem, acertaste, Caso contrário... perdeste!
$10^{*}$ - Sou um bom processo Físico de separação, Deixo passar a água, Mas os resíduos não!...

$11^{*}$ - Qual é coisa qual é ela Que permite separar Dois líquidos imisciveis E ambos aproveitar?

12 - Sou uma partícula pequena Tiraram-me um electrão. Por ter carga há uma "cena": Por iguais sinto repulsão. Alguém catião me chamou. Adivinhem que eu sou.

13 - Ando a alta velocidade Desapareço de repente. Sem mim não há electricidade Posi eu é que crio corrente. Sou de pequeno tamanho, De correr tenho vontade, Adivinhem que nome tenho No bilhete de identidade.

$14^{*}$ - Do átomo já estou farto Mas que grandes confusões. Juntei neutrões com protões Só me faltam ...

15 - Sou uma unidade Para porção de substância. Pensa no oposto de rijo, Estarás a pouca distância ...

16 - Sou comprido quando escrito, Um italiano me baptizou, $E$ fiquei quase infinito. Se quiseres contar quantos sou, Dás cabo dos teus miolos. Um tal número de tijolos Até chega a Plutão. Qual será a solução?

17 - Se fria eu dou frescura E o sal em mim se mete. Com 100 graus vou à fervura E também limpo a retrete. Quando existo mesmo pura, 0 meu pH vale sete. 


\section{e n s i n 0}

$18^{*}$ - Lá que a massa total Dos reagentes será Igual à dos produtos, Dúvidas não haverá. Mas quem disse isto Muito esperto será. "Qui a dit cela"?

\section{$19^{*}$ - Era francês}

(Não português...)

Acertava equações Nas suas ocupações. Inventou então uma lei Que eu agora também sei.

20 - Sempre que eu aconteço Novas substâncias há. Não sei com quem me pareço, Quem sou eu, quem me dirá?

21 - Quando eu aconteci Energia ao exterior dei. Diz lá, agora e aqui Que "desgraça" serei.
$22^{*}$ - Quando chocam eu me formo. Sou o resultado final Do choque de moléculas Reagentes em geral. Mas depois de tudo isto, Quem serei eu afinal?

$23^{*}$ - Eu cá tenho uma teoria Que trata de reacções. Ao choque remeterá Esta minha teoria, que só tem uma mania É de dar "encontrões" Que teoria será?

24 - Sou um pobre indicador Sou claro e transparente. Com base mudo de cor ... Viro vermelho de repente.

$25^{*}$ - De tantas escalas diferentes Apenas uma há Que entre ácido e base Concerteza escolherá. Mas que escala é que será? ...

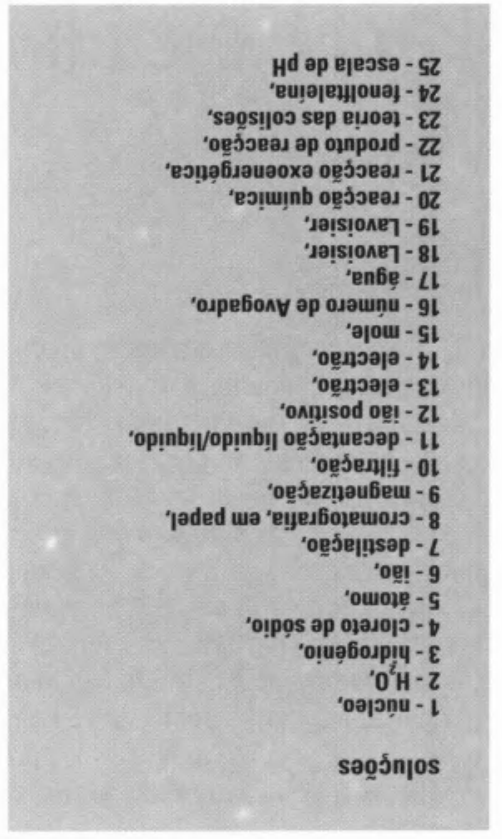

* Escola Secundária de Penacova 3360 PENACOVA

\section{TITRINO DMS 716}

RESOLVE A DINÂMICA DA TITULAÇÃO

Oferece cinco métodos básicos

* DET - Titulação Dinâmica de Ponto de Equivalência

* MET - Titulação Monotónica do Ponto de Equivalência

* Polarizador incorporado para Titulações Amperométricas/Voltamétricas

* Determinação pK para Ácidos e Bases fracas

* Interface RS 232C incorporada para ligação a Balança, OC, Printer, etc.

* Memória não volátil de métodos e dados

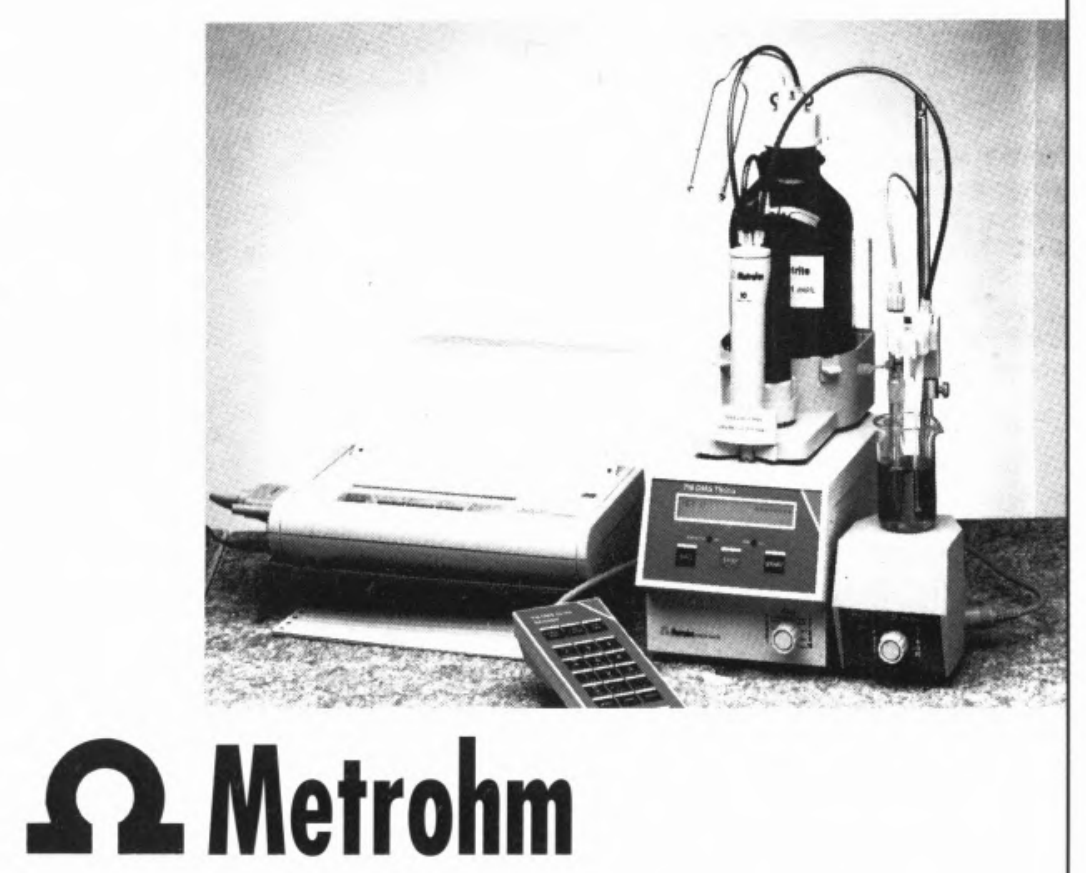

